\title{
Science communication between risk and (un)certainty
}

Conference

Reviewd by

Abstract

\author{
$2^{\text {ND }}$ ANNUAL CONFERENCE OF THE AD HOC GROUP SCIENCE COMMUNICATION OF \\ THE GERMAN COMMUNICATION ASSOCIATION (DGPUK), \\ Jena, Germany, 30-31 January 2015
}

\section{Corinna Lüthje}

The $2^{\text {nd }}$ annual conference of the ad hoc group Science Communication was dedicated to research on risk and uncertainty as important challenges for the present practice of science communication. The review firstly offers a short portrait of the ad hoc group Science Communicaiton as a newly established network of communication scholars and secondly reconstructs the course of the highliy spirited debate during the conference in Jena.

The ad hoc group Science Communication was established in 2012. The motivation for its formation was in part that science communication is becoming more and more important but (at least in the German-speaking area) mainly it has become an important profession and realm of practice. At the same time science communication as an area of communication research is still a largely neglected field. I knew about a few colleagues who do research in science communication, but we were working in isolation. We felt the need for an institution for networking, discussing and reflecting and also as a competent contact partner for practitioners. Together we have a wide comprehension of science communication; we are concerned with scholarly as well as science communication. We also deal with specific topics such as risks, environment, climate, sustainability, catastrophes, and the consequences of technology. As we are still at an early phase, we try to identify open topics for our conferences, so as to integrate many different perspectives and to stimulate the discussion between participants who come from diverse areas of science communication (for example journalism, PR, reception, communication history, the sociology of communication etc.). The first workshop oft he AhG Science Communication took place in January 2013 and was entitled "Science communication and communication sciences: perspectives and challenges". The first official annual convention was held in 2014 in Zürich and was about "Changes in Science communication".

The second annual convention was recently held in Jena and was organized by Georg Ruhrmann, Sabrina Heike Kessler and Lars Guenther. The topic "Science communication between risk and (un)certainty" was a continuation of the debates begun in Berlin and Zürich. Nineteen presentations were distributed in five groups. All the panels were presented in plenary sessions so as to allow the 60 participants 
the chance to hear them all and to take part in the debate. This led to creative and animated discussions.

Ortwin Renn's keynote pointed out the relevance and topicality of the convention's topic. In democratic societies risks to society are a high profile concern and more participation is demanded. Yet scientists often complain that the lay person's perception of risks doesn't match risk assessments made by experts. This discrepancy represents a challenge for risk communication, which Ortwin Renn described using terms such as 'complexity, uncertainty and ambiguity'. Complexity means that serious damage cannot usually be attributed to just one specific cause, but is rather the result of elaborate chains of cause and effect. It is difficult to communicate such complex mechanisms in simple language. The challenge for risk communication is to explain complicated connections in a simple, up to date and concise manner; the explanations often seem improbable, cannot be expressed in a simple narrative and do not seem relevant. The problem about the uncertainty that results from complexity is that we can easily ignore the findings of risk analysis. There are exceptions for every trend that has been described, often in one's own experience, and those exceptions can lead us to maintain risky habits (e.g. smoking). Ambiguity, even if there is a scientific consensus, leaves considerable room for interpretation in the meaning of results and their classification. Ortwin Renn's conclusion is that discussion is still needed about which risks are reasonable for whom.

The second keynote lecture, by Emma Weitkamp, gave many practical examples, to show the challenges for science communication that are associated with the increase in scientific PR and the transformation of media technology. 'Media' as a topic concerns the role of new media and social media in the development of science communication. In addition, Emma Weitkamp raised the issue of how the relationship between scientific PR and science journalism is changing. Does popularization of knowledge develop into "research for sale"? What role does media training for scientists and spin doctors play in the selection and processing of knowledge for the public?

The panels were grouped for consideration of two issues: risk and science communication. In the first panel the debate focused on the perspectives of journalists and communicators. I found the different research areas and their specific relationship with scientific uncertainty particularly interesting. Christoph Klimmt et al. reported about the problems of journalistic assessment of evidence in social science. The other two presentations in this panel were about neuroscience (Markus Lehmkuhl and Hans Peter Peters) and biotechnology (Senja Post and Michaela Maier). The second panel focused on media representations of science and the third panel on strategies for presentation. Further issues for discussion were the development of a procedure for the systematic evaluation of quality in science journalism (Holger Wormer, Markus Annhäuser and Julia Serong) and the importance of trust in a society concerned with risks presented in the media (Beatrice Dernbach). Julia Metag and Mike S. Schäfer emphasized the importance of visual scientific demonstrations. They presented Q-methodology: an exciting, innovative approach for studying the effects of 'visualization' of science. Sabrina Heike Kessler, Doreen Reifegerste and Lars Guenther talked about the power of images in science communication. The fourth panel was about the reception of 
news between risks und (un)certainty. Finally, the fifth panel was dedicated to audience and reception research.

For the round-table discussion, the last item on the agenda, Georg Ruhrmann invited science philosopher Wolfgang van den Daele, Elisabeth Hoffmann, an exponent of science PR and a science journalist Sabine Goldhahn. During the debate the topics of the convention were efficiently recapitulated and clarified from the different perspectives of science communication represented by the participants.

To sum up, I can say that the meeting in Jena has provided a good insight into various positions in the research field of science communication. One obvious conclusion might be that there are very few empirical studies concerning important current challenges in science communication. There is a lack of research regarding the reception and impact of science communication, the role of social media and the special properties of science PR.

Risk and uncertainty are important considerations for practical issues as well as for research in science communication. More communication research is needed on science communication and also more communications science communication that is addressed to practitioners and that accurately reflects research findings. The debate of the AhG Science Communication in the DGPuK continues. The next annual meeting will take place in January 2016 in Dresden. The theme will concern the role of various disciplines in science communication.

\section{Translated by Gei Sohie}

Revised by John Nicholls

Author

How to cite

This article is licensed under the terms of the Creative Commons Attribution - NonCommercial NoDerivativeWorks 4.0 License.

ISSN 1824 - 2049. Published by SISSA Medialab. http:/ /jcom.sissa.it/. 